\title{
MATERIAL WITNESS
}

\section{Poison plastic?}

Sir Richard Doll, the British epidemiologist who linked smoking with lung cancer, has recently been accused of holding undisclosed contracts with various companies and industries while assessing the safety of their products. The insinuation that this compromised the integrity of his research has been disputed, and certainly it's not clear that Doll, who died in 2005, can be judged by today's standards on conflicts of interest. Quite aside from questions of conduct, however, the affair raises the vexed issue of the toxicology of polyvinyl chloride, arguably the most environmentally controversial polymer in widespread use.

PVC is now ubiquitous. The second most widely used plastic, it is found in everything from house plumbing to biomedical equipment, clothing and 'vinyl' gramophone records. But the plastic has been under threat ever since it was found in 1972 that its constituent monomer, vinyl chloride, might cause liver cancer.

Fear of regulation led the Chemical Manufacturers Association to commission a safety review of PVC from Doll in the mid-1980s. In 1988 he concluded that there was no evidence that vinyl chloride causes other cancers; Doll's report is still cited today in support of the safety of its manufacture vinyl chloride.

Yet the safety of PVC has become a battleground. In 1982 several chemicals companies set up the Vinyl Institute to defend its reputation, whereas Greenpeace has called PVC the 'poison plastic' and campaigns for its phase-out. It says that both the production and incineration of PVC produce dioxins, which are toxic carcinogens. PVC waste has been implicated in dioxin release from landfills.

That's a criticism not of the plastic itself but the way it is made and disposed of. But products made from PVC have also been attacked because of the plasticizing additives, particularly phthalates, which are again thought to be potential carcinogens. Concerns that these may leach out when children chew soft toys made from PVC led the European Union to ban some such plasticizers from toys in 2006; some toy companies have stopped using PVC voluntarily. (My child's bath-friendly book comes with the label 'PVC-free'.)
Yet these claims too are disputed. In 1998 the US Consumer Product Safety Commission said that the amount of phthalates that might leach from vinyl toys doesn't even come close to the danger level; in 1999 the American Council on Science (6) and Health declared them safe.

These arguments are going to be resolved not by science but by the marketplace: mere suspicion of danger is now enough to put consumers off. It's surely this that has motivated companies such as Microsoft and Wal-Mart to phase out PVC from their products. 'PVC-free' labels, whether needed or not, send out a clear message that PVC is bad. No one could really call PVC green, and if there are better alternatives, maybe it is good to use them. Yet this seems to be another instance of society wanting to put materials into boxes labelled 'good' and 'bad' rather than facing the full complexities of their manufacture and use.

Philip Ball

\section{ERRATUM}

\section{A lesson from virtual zeolites}

IGOR RIVIN

Nature Materials 5, 931-932 (2006)

In this News \& Views article, Fig. 2 was missing; it should have appeared as shown here. Both Figs 1 and 2 should also be credited to M. M. J. Treacy.

a

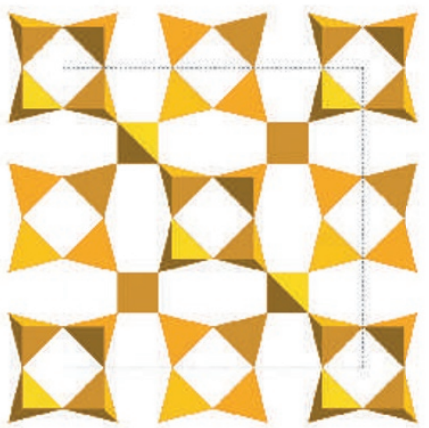

b

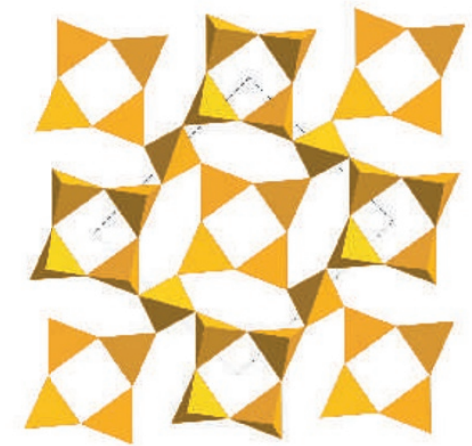

Figure 2 Zeolites that don't like symmetry. The framework of a zeolite known as AST. a, The idealized cubic form with the corner-sharing tetrahedra visible. b, The framework relaxes into a tetragonal framework (with lower symmetry) by tilting the tetrahedra. For both $\mathbf{a}$ and $\mathbf{b}$, the view is down the tetragonal $c$ axis and the tetragonal unit cell is outlined. The tetragonal form has a wider flexibility window than the cubic. 